\title{
PENGEMBANGAN LEMBAR KERJA PESERTA DIDIK BERDASARKAN KAJIAN EKOSISTEM MANGROVE DI KAWASAN TAMAN WISATA ALAM PANTAI PANJANG BENGKULU
}

\author{
AR Acep Pebri ${ }^{1 *}$, Kasrina ${ }^{1}$, dan Irdam Idrus ${ }^{1}$ \\ ${ }^{1}$ Program Studi Pendidikan Biologi, Fakultas Keguruan dan Ilmu Pendidikan, Universitas Bengkulu \\ Email : putrabio20@gmail.com
}

\begin{abstract}
Abstrak
Penelitian ini bertujuan untuk 1). Mendeskripsikan faktor abiotik dan biotik pada ekosistem mangrove di kawasan taman wisata alam (TWA) Bengkulu; 2). Mengetahui kelayakan Lembar Kerja Peserta Didik (LKPD) materi ekosistem berdasarkan hasil observasi ekosistem mangrove di kawasan TWA Pantai Panjang Bengkulu. Berdasarkan hasil penelitian faktor abiotik pada kawasan TWA Pantai Panjang adalah sebagai berikut: intensitas cahaya $=230-235 \mathrm{Cd}, \mathrm{pH}$ tanah $=5,0-6,5$, dan suhu udara $=30,5-33 \cdot 5^{\circ} \mathrm{C}$. Komunitas hewan yang ditemukan adalah salamander, kepiting, klomang, dan serangga. Hasil validasi LKPD oleh 3 validator menunjukkan persentase $84 \%$ dengan kriteria sangat valid. Hasil uji keterbacaan pada 30 orang peserta didik menunjukkan persentase $92 \%$ dengan kriteria sangat baik. Berdasarkan persentase hasil validasi oleh ahli dan uji keterbacaan dapat disimpulkan bahwa LKPD yang dikembangkan layak digunakan sebagai bahan ajar pada materi ekosistem kelas X Sekolah Menengah Atas.
\end{abstract}

Kata kunci: Lembar kerja peserta didik, ekosistem mangrove, TWA Pantai Panjang

\begin{abstract}
This research aims to 1). Describing the abiotic and biotic factors on the mangrove ecosystem in nature tourism park (TWA) Pantai Panjang. 2). Find out the appropriateness of Students' Work Sheet (LKPD) that was designed based on the observation result of mangrove ecosystem in TWA Pantai Panjang. Based on the result of the research, it was found the abiotic factors on the mangrove ecosystem of TWA Pantai Panjang as follow: light intensity $=230-235 \mathrm{Cd}$, soil $\mathrm{pH}=5.0-6.5$, air temperature $30.5-33.5^{\circ} \mathrm{C}$. The animal communities that were found are salamander, crab, hermit crab, and insect. The designed LKPD was classified by 3 validators as very valid showing the percentage of $84 \%$. The readability test on this LKPD by 30 students showed the result as very good with percentage of $92 \%$. Based on the validity and readability result, it can be concluded that the designed LKPD is feasible to be used as a teaching material on the ecosystem topic in $X$ grade of Senior High School.
\end{abstract}

Keywords: Students work sheet, mangrove ecosystem, TWA Pantai Panjang 


\section{PENDAHULUAN}

Lingkungan alam sekitar peserta didik merupakan potensi lokal yang dapat dimanfaatkan sebagai sumber belajar. Potensi lokal merupakan sumber daya yang dalam suatu wilayah tertentu. Potensi lokal tidak terlepas dari konsep lingkungan sebagai pendukung untuk berlangsungnya proses pembelajaran. Potensi lokal, baik hewan maupun tumbuhan, yang terdapat di lingkungan sekolah dapat menjadi objek belajar bagi peserta didik dan dapat dikaitkan dengan materi pembelajaran (Victorino, 2004).

Kota Bengkulu merupakan daerah pesisir pantai yang memiliki potensi lokal hutan mangrove. Mangrove merupakan salah satu sumber daya penting di wilayah pesisir yang memiliki peranan vital sebagai katalis ekosistem untuk zona daratannya. Keberadaan mangrove memberikan fungsi ekologis dalam hal memproduksi nutrient yang dapat menyuburkan perairan laut, membantu perputaran karbon, dan tempat perkembangbiakan dan pembesaran bagi beberapa spesies ikan. Ekosistem mangrove juga berfungsi sebagai pelindung alami wilayah daratan dari ancaman tsunami dan gelombang pasang. Disisi lain ekosistem mangrove juga memiliki tingkat ancaman, kerentanan, serta tekanan yang sangat tinggi yang dipicu oleh faktor ekonomi jangka pendek dan tidak berkelanjutan (Murtini, 2015).

Hutan mangrove dapat dimanfaatkan sebagai sumber belajar bagi peserta didik (Rahmat, 2015), khususnya pada materi ekosistem. Berbagai jenis tumbuhan pada hutan mangrove dapat memberikan gambaran tentang konsep ekosistem. Materi ekosistem mempelajari keberagaman makhluk hidup pada tingkatan gen, jenis, dan ekosistem. Hal ini sesuai dengan KD pada K.13 yaitu 3.9. Menganalisis informasi/data dari berbagai sumber tentang ekosistem dan semua interaksi yang berlangsung didalam nya.

Salah satu upaya dalam meningkatkan pemahaman materi ekosistem adalah penggunaan bahan ajar berupa Lembar Kegiatan Peserta Didik (LKPD). LKPD ini dapat dikembangkan dengan hasil studi ekosistem mangrove berdasarkan pengukuran pada faktor abiotik dan biotik.

Berdasarkan wawancara peneliti terhadap Guru IImu Pengetahuan Alam (IPA) di SMAN 1 Kota Bengkulu, penggunaan LKPD berbasis potensi lokal belum pernah digunakan. Selama ini guru hanya menggunakan LKPD dari penerbit yang kurang sesuai dengan keadaan peserta didik dan lingkungan sekolah. Hal ini dapat menyebabkan peserta didik kurang memahami konsep dan teori-teori yang ada pada LKPD tersebut.

Hal ini dapat diatasi dengan penggunaan LKPD yang dikembangkan berbasis penelitian atau studi lapangan di lingkungan sekitar peserta didik. Hasil penelitian Rahmat (2015) menunjukan bahwa kualitas LKPD dengan materi ekosistem termasuk dalam kategori sangat baik. Sesuai kurikulum 2013 peserta didik dituntut agar dapat menemukan konsep pengetahuan secara mandiri dari kegiatan yang dapat merangsang kemampuan berpikirnya.

LKPD merupakan kumpulan dari lembaran yang berisikan kegiatan peserta didik yang memungkinkan peserta didik melakukan aktivitas nyata dengan objek dan persoalan yang dipelajari. LKPD berfungsi sebagai panduan belajar peserta didik dan juga memudahkan peserta didik dan guru melakukan kegiatan belajar mengajar. LKPD juga dapat didefenisikan sebagai bahan ajar cetak berupa lembar-lembar kertas yang berisi materi, ringkasan, dan petunjukpetunjuk pelaksanaan tugas yang harus dikerjakan oleh peserta didik, yang mengacu pada kompetensi dasar yang dicapai (Prastowo, 2011).

Bahan ajar LKPD sangat cocok jika digunakan dalam pembelajaran Biologi SMA. Karakteristik LKPD bersifat sistematis, runut dan mampu menjadikan materi Biologi yang rumit menjadi sederhana. Guru dapat menyusun dan mengembangkan LKPD disesuaikan dengan kebutuhan serta keadaan sekolah. Setiap sumber belajar Biologi didampingi dengan bahan ajar LKPD untuk menyederhanakan materi pembelajaran. Pembelajaran Biologi akan 
menjadi lebih menarik, karena contohcontoh yang diambil sangat dekat dengan kehidupan peserta didik dan bersifat kontekstual. Menurut Prastowo (2009), LKPD dapat menyeimbangkan antara proses dan produk pembelajaran karena memandu peserta didik melakukan kegiatan pembelajaran dan memberikan pengalamaan belajar.

Tujuan penelitian ini adalah untuk Mengembangkan lembar kerja peserta didik berdasarkan hasil studi ekosistem mangrove dikawasan taman wisata alam pantai panjang Bengkulu

\section{METODE}

Penelitian ini merupakan jenis Penelitian dan pengembangan (Research and Development). Langkah-langkah penelitian yaitu, 1. Potensi dan Masalah; 2. Pengumpulan Data; 3. Desain Produk; 4. Validasi Desain; 5. Revisi Desain; 6. Uji Coba Produk; dan 7. Revisi Produk.

Subjek penelitian dalam penelitian ini adalah peserta didik kelas X IPA 1 SMAN1 Kota Bengkulu yang berjumlah 30 orang peserta didik. Teknik pengumpulan data untuk faktor abiotik berupa pengukuran di lapangan. Pengukuran faktor abiotik dilakukan pada 3 faktor abiotik pada ekosistem mangrove yaitu pada intensitas cahaya, $\mathrm{pH}$ tanah, dan kelembaban udara. Selanjutnya data jenis tanaman yang didapatkan dikembangkan menjadi suatu bahan ajar yaitu Lembar Kegiatan Peserta Didik (LKPD).

Jenis LKPD yang dikembangkan adalah LKPD eskperimen. LKPD eksperimen yaitu LKPD praktis yang digunakan sebagai panduan kerja lapangan disertai dengan alat dan bahan yang akan digunakan. Hal ini sesuai dengan Devi (2009) yaitu, LKPD eksperimen berupa lembar kerja yang memuat petunjuk praktikum yang menggunakan alat-alat dan bahan-bahan. LKPD yang dikembangkan merupakan LKPD materi Ekosistem dengan KD 3.9. Menganalisis informasi/data dari berbagai sumber tentang ekosistem dan semua interaksi yang berlangsung didalam nya. adapun indikator pembelajarannya yaitu 3.9.1 Menjelaskan faktor abiotik dan biotik pada ekosistem. 3.9.2 Menjelaskan apa saja penyusun dari komponen ekosistem.

LKPD ini berfungsi sebagai bahan ajar yang membuat peserta didik lebih aktif, mempermudah peserta didik memahami materi, dan memudahkan proses pembelajaran. Hal ini sesuai dengan Prastowo (2011) dimana LKPD seharusnya berfungsi sebagai bahan ajar yang mengaktifkan peserta didik, memudahkan peserta didik dalam memahami materi ajar, dan memudahkanpelaksanaan proses pengajaran. Instrumen yang digunakan untuk mengetahui kelayakan LKPD yang telah dikembangkan adalah lembar angket validasi. Validasi LKPD dilakukan oleh 2 orang dosen ahli dan 1 orang guru biologi. Data Hasil Validasi Oleh Dosen Ahli Dan Guru Biologi dianalisa menggunakan rumus:

Skor $=\frac{\text { Skor dari validator }}{\text { Skor maksimal }} \times 100 \%$

(Riduwan, 2015).

Skor dari validator kemudian dirataratakan, dan selanjutnya diinterpretasikan dalam kategori kualitatif sesuai Tabel 1.

Tabel 1. Kriteria Interpretasi Skor

\begin{tabular}{cc}
\hline Presentase & Kriteria \\
\hline $0 \%-20 \%$ & Sangat Tidak Valid / Sangat \\
& Tidak Baik \\
$21 \%-40 \%$ & Tidak Valid / Tidak Baik \\
$41 \%-60 \%$ & Cukup Valid / Cukup Baik \\
$61 \%-80 \%$ & Valid / Baik \\
$81 \%-100 \%$ & Sangat Valid / Sangat Baik \\
\hline & Riduwan (2015).
\end{tabular}

\section{HASIL DAN PEMBAHASAN}

Berdasarkan hasil penelitian tentang ekosistem mangrove di kawasan Taman Wisata Alam (TWA) Pantai Panjang Bengkulu di temukan 4 spesies tumbuhan Mangrove yang tumbuh di lingkungan dengan kondisi yang berbeda-beda. Ditemukan juga hewan seperti salamander, kepiting, klomang, dan serangga yang menempati wilayah pada ekosistem mangrove.

Desain LKPD yang disusun mengalami penyempurnaan antara sebelum dan sesudah divalidasi hal ini dapat dilihat pada Gambar 1. 

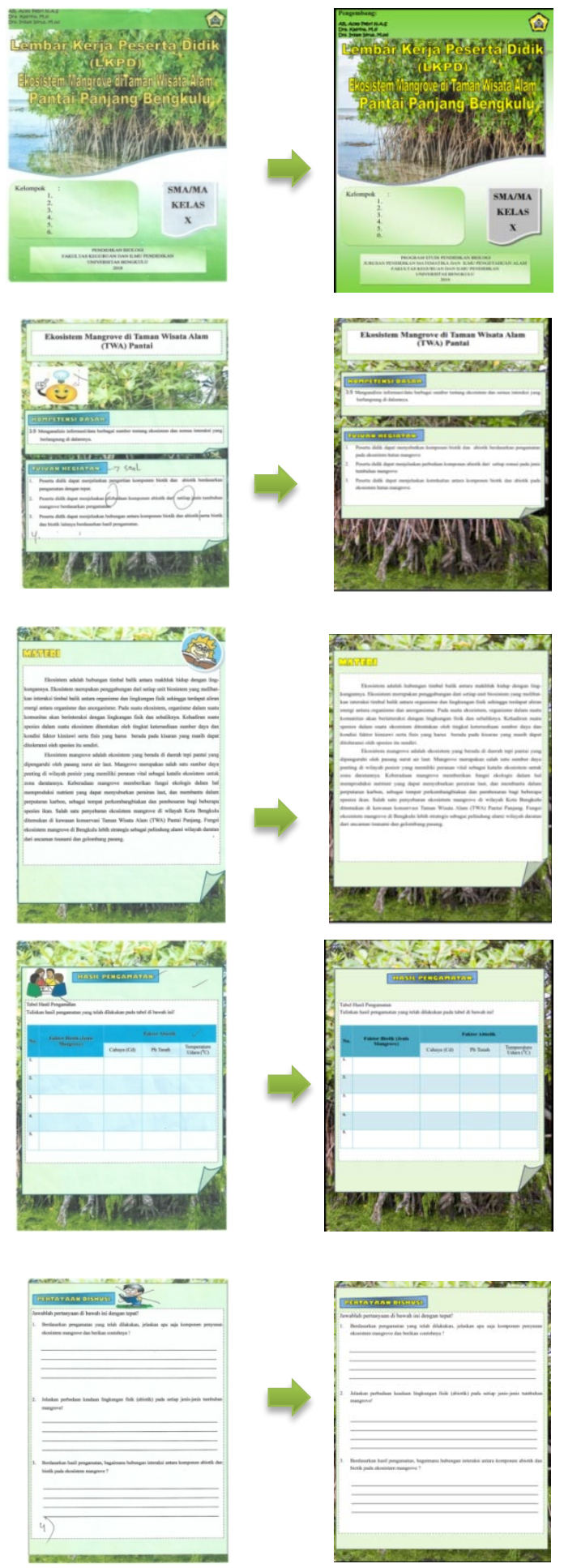

Gambar 1. Perbandingan Desain LKPD sebelum dan Sesudah Divalidasi

Pada cover LKPD terdapat judul, mata pelajaran, serta kelas peserta didik untuk memudahkan peserta didik mengetahui informasi dan kegiatan inti di dalam LKPD. Pada cover juga diletakkan beberapa gambar tumbuhan yang terdapat dilokasi penelitian agar desain LKPD lebih menarik dan memotivasi peserta didik. Menurut Kurniawan (2015) desain cover harus menarik karena peserta didik akan terlebih dahulu melihat tampilan cover LKPD. Pada isi LKPD terdapat beberapa komponen antara lain kompetensi dasar, tujuan, materi pokok, alat dan bahan, cara kerja, hasil, pertanyaan, dan kesimpulan. Sesuai dengan komponen LKPD yang baik menurut Depdiknas (2008).

Pada LKPD terdapat bagian materi yang memuat spesies tanaman, baik yang merupakan hasil penelitian di TWA Pantai Panjang Bengkulu maupun tidak. LKPD juga disertai dengan lampiran gambar panduan zonasi spesies tumbuhan mangrove yang bertujuan untuk membantu peserta didik dalam melakukan pengamatan faktor abiotik . Merujuk kepada panduan praktikum Team Kreatif Biologi (2016) suatu LKPD yang baik memiliki lembar panduan yang membantu peserta didik dalam proses pengamatan.

LKPD yang dikembangkan peneliti memiliki beberapa keunggulan dibandingkan LKPD penerbit, yaitu dari aspek desain tampilan, aspek materi, aspek komponen penyusun LKPD. Keunggulan utama LKPD hasil pengembangan dibuat berdasarkan penelitian dari objek lingkungan sekitar yang telah diteliti sebelumnya. Pemanfaatan lingkungan dapat mengembangkan sejumlah keterampilan, seperti mengamati (dengan seluruh indera), mencatat, merumuskan pertanyaan, berhipotesis, mengklasifikasikan, membuat tulisan, dan membuat gambar/diagram (Uno dan Mohamad, 2014).

Desain tampilan LKPD hasil pengembangan lebih menarik, gambar atau ilustrasi yang disajikan lebih beragam dan diberi warna sehingga lebih menarik minat peserta didik. Terbukti dengan hasil angket uji validitas oleh validator dengan skor diatas rata-rata pada kelayakan materi (skor minimum 21), penyajian materi (skor minimum 15), penampilan (skor minimum 15) dan desain grafis (skor minimum 36). Hasil angket uji keterbacaan oleh peserta didik juga memiliki skor diatas rata-rata pada aspek penampilan (skor minimum 15). Menurut Salirawati (2004) penampilan sangat penting dalam LKPD karena merupakan hal yang pertama kali dilihat oleh peserta didik. Menurut Wibowo (2013) LKPD yang baik menggunakan lebih banyak ilustrasi dibandingkan dengan kata-kata. 
Materi LKPD hasil pengembangan membahas seluruh cakupan materi Ekosistem yang diperlukan peserta didik sehingga pengetahuan yang diperoleh tercukupi. Perbandingan beberapa komponen LKPD penerbit dengan LKPD hasil pengembangan dapat dilihat pada Gambar 2.
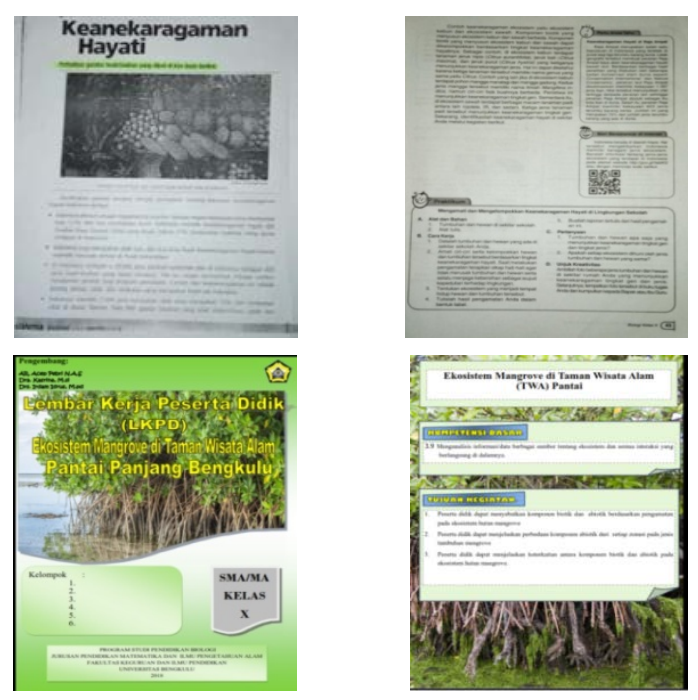

Gambar 2. Perbandingan beberapa komponen LKPD hasil pengembangan (kiri) dengan LKPD penerbit (kanan)

\section{Uji validitas LKPD}

Berdasarkan uji validitas yang telah dilakukan, validator I menilai LKPD yang didesain termasuk kriteria valid dengan presentase hasil angket sebesar $73 \%$. Validator II memberikan penilaian yang lebih baik yaitu sangat valid dengan presentase hasil angket sebesar $85 \%$. Validator III memberikan kriteria sangat valid dengan persentase hasil angket sebesar $95 \%$.

Secara keseluruhan berdasarkan uji validitas oleh ketiga validator telah LKPD termasuk kriteria sangat valid dengan persentase hasil angket sebesar $84 \%$. Menurut hasil angket ketiga validator menilai LKPD telah baik dari aspek kelayakan materi, penyajian materi, kebahasaan, penampilan, dan desain grafis. Hal ini membuktikan bahwa LKPD yang telah didesain secara rasional lebih efektif, sesuai dengan tujuan uji validitas menurut Sugiyono(2008).

\section{Uji keterbacaan LKPD}

Setelah LKPD divalidasi dan direvisi berdasarkan hasil uji validitas selanjutnya dilakukan uji keterbacaan oleh peserta didik kelas X IPA 1 SMAN 1 kota Bengkulu. Hasil angket uji ketebacaan LKPD oleh peserta didik dapat dilihat pada Tabel 3.

Tabel 3. Uji Keterbacaan LKPD Peserta Didik

\begin{tabular}{llcc}
\hline No. & Aspek Penilaian & Persentase Setuju & Kriteria Kualitatif \\
\hline 1. & $\begin{array}{l}\text { Apakah susunan kalimat pada LKPD mudah } \\
\text { dipahami dan jelas? }\end{array}$ & 100 & Sangat baik \\
2. $\quad \begin{array}{l}\text { Apakah petunjuk dan prosedur pada LKPD ini } \\
\text { sudah jelas? }\end{array}$ & 96 & Sangat baik \\
3. $\quad \begin{array}{l}\text { Apakah materi menarik dan menambah wawasan } \\
\text { tentang Ekosistem Mangrove? }\end{array}$ & 93 & Sangat baik \\
4pakah gambar di dalam LKPD memiliki kejelasan \\
$\begin{array}{l}\text { dan kelengkapan keterangan? } \\
\text { Apakah contoh Ekosistem Mangrove yang } \\
\text { disajikan pada LKPD sudah cocok dengan tingkat } \\
\text { Ekosistem? }\end{array}$
\end{tabular}


Berdasarkan uji keterbacaan, aspek kebahasaan LKPD memperoleh nilai $100 \%$ yang menandakan kriteria sangat baik. Aspek 2,5,10 (prosedur, contoh dan kualitas cetakan) mendapatkan persentase 96\%. Pada aspek 3,4,7 dan 8 (materi, gambar, bahasa, dan layout) mendapatkan persentase 93\%. Secara keseluruhan berdasarkan hasil angket dari 30 orang peserta didik, LKPD yang telah didesain termasuk kriteria sangat baik dengan persentase 92\%. Hal ini menandakan bahwa LKPD telah dapat digunakan dalam pembelajaran. LKPD yang telah didesain telah memenuhi persyaratan dari beberapa aspek yang terdapat pada angket uji keterbacaan yaitu penampilan, penyajian, materi, dan bahasa. Menurut Sugiyono (2008). Uji keterbacaan dilakukan untuk melihat apakah LKPD tersebut sudah baik dan dapat digunakan untuk peserta didik dalam pembelajaran.

Sebagian peserta didik yang mengisi angket pada kolom kritik dan saran, memberikan pedapat bahwa LKPD yang didesain memeliki cover, dan penggunaan warna yang menarik, gambar dan tabel yang disajukan jelas, materi disajikan menarik, dan isi LKPD mudah dipahami dan disajukan secara jelas dan rinci. Secara keselurahan peserta didik tertarik, termotivasi, menyukai, memahami, dan mertasa LKPD tersebut dapat menambah wawasan dan pengetahuan mereka. Namun terdapat saran dari beberapa peserta didik yaitu pada bagian lampiran pada LKPD yaitu untuk menambah contoh lagi dari spesies tumbuhan lainnya.

\section{PENUTUP}

\section{Kesimpulan}

Beberapa jenis tumbuhan mangrove yang ditemukan di kawasan Taman Wisata Alam Pantai Panjang Bengkulu adalah Rhizophora apiculata, Sonneratia alba, Bruguiera cylindrical, dan
Acanthus ebracteatus. Jenis hewan yang ditemukan antar lain salamander, klomang, kepiting, dan semut. Pada faktor abiotik didapatkan data rata-rata yaitu intensitas cahaya $230-235 \mathrm{Cd}, \mathrm{pH}$ tanah 5,0-6,5 dan suhu $30,5-33,5^{\circ} \mathrm{C}$. Desain LKPD hasil studi Ekosistem Mangrove di kawasan Taman Wisata Alam Pantai Panjang Kota Bengkulu layak digunakan dalam pembelajaran dengan nilai persentase $84 \%$ oleh validator dan nilai persentase $92 \%$ dalam uji keterbacaan para peserta didik

\section{Saran}

Lembar kerja peserta didik (LKPD) yang telah didesain dapat digunakan untuk penelitian selanjutnya yaitu penelitian implementasi atau penerapan bahan ajar untuk peserta didik kelas X SMA materi Ekosistem.

\section{DAFTAR PUSTAKA}

Depdiknas. 2008. Panduan Pengembangan Bahan Ajar. Jakarta: Direktorat Pembinaan Sekolah Menengah Atas.

Devi, P.K., R. Sofiraeni, Khairuddin. 2009. Pengembangan Perangkat Pembelajaran untuk Guru SMP.Bandung: PPPPTK IPA.

Kurniawan, Agus. 2015. Pengembangan Lembar Kerja Peserta Didik, (www.respository.ump.ac.id).

Murtini, Sri. 2015. pengembangan ekowisata mangrove wonorejo untuk media pembelajaran melalui pendekatan berbasis masyarakat. Journal of Biology Education (www.journal.unnes.ac.id).

Prastowo,A. 2011. Panduan Kreatif Membuat Bahan Ajar Inovatif. Jogjakarta: Diva Press.

Rahmat, 2015. Pengembangan Lembar Kerja Peserta Didik (LKPD) Biologi Berbasis Potensi Lokal Hutan Mangrove dengan 
Strategi Discovery Learning pada Materi Pokok Ekosistem untuk Kelas $X$ di SMA Negeri 1 Popayato. Jurnal Pendidikan Universitas Negeri Gorontalo

Republika. 2012. Sekolah Dilarang Jual Belikan LKS, (www.republika.co.id)

Riduwan. 2015. Skala Pengukuran Variabel-variabel Penelitian. Bandung: Alfabeta

Salirawati, Das. 2004. Penyusunan dan Kegunaan LKS dalam Proses Pembelajaran, (www.staffnew.uny.ac.id)

Sugiyono. 2008. Metode Penelitian Pendidikan (Pendekatan Kuantitatif, Kualitatif, dan R\&D). Bandung: Alfabeta

Team Kreatif Biologi. 2016. Panduan Praktikum Biologi SMA/MA Kelas X. Jakarta: Bumi Aksara.

Uno, H.B., N. Mohamad, 2014. Belajar dengan Pendekatan PAILKEM. Jakarta: Bumi Aksara.

Victorino, D. 2004. Global Responsibility and Local Knowledge System. Conference held in Egypt.

Wibowo,W.S. 2013. Pengembangan Perangkat Pembelajaran IPA Terpadu Guna Mendukung Pelaksanaan Kurikulum 2013. Makalah disajikan dalam PPM "Workshop Pengembangan Perangkat Pembelajaran IPA Terpadu bagi Guru SMP/MTS 